\title{
Research on the development status of Korean language training industry in Wuhan
}

\author{
An Feng ${ }^{1, a}$, Zhao HaiBo ${ }^{2, b}$ \\ ${ }^{1}$ School of economics and business English, Wuhan Technology and Business University, Wuhan, \\ 430065, China \\ 2 School of Foreign languages, South-Central University for Nationalities, Wuhan, 430074, China \\ a826084548@qq.com, b 935069349@qq.com
}

\section{Keywords: Korean training, Korean employment, Wuhan Korean education}

\begin{abstract}
This paper focuses on the Korean language training industry in Wuhan, through field research, I learned about the operation scale, employment form, teacher status, enrollment status, profit and loss status, market demand and problems to be overcome in the Korean language training service industry in Wuhan. In this way, the prospect of Korean education service industry in Wuhan and the feasible strategy of starting a business are analyzed, which provides abundant and powerful empirical evidences for the following Korean majors to start a business and obtain employment.
\end{abstract}

\section{Introduction}

With the gradual deepening of China's opening up to the outside world, the demand for foreign language education is constantly increasing, from a single UK Language language-oriented, gradually developed into the features of the needs of small language inclination. Especially in recent years, in response to the booming demand for economic, trade and cultural exchanges between China and South Korea, young students have become increasingly enthusiastic about learning Korean. 180 colleges and universities have established Korean majors, and the number of students studying in South Korea has increased year by year.

Wuhan is the capital city of Hubei province, a central city in central China, an important industrial base, a scientific and educational base and a comprehensive transportation hub in China. Due to its unique geographical location and cultural and economic characteristics, Wuhan has not only formed special regional culture, commercial culture, open city culture and innovative urban spirit, which makes Wuhan people keep a willingness to try and welcome foreign Korean food, movies, cosmetics and etiquette culture. Meanwhile, as one of the largest education bases in China, Wuhan has a large group of students and a learning atmosphere. This provides sufficient market conditions for Korean education training industry to enter Wuhan region.

Since Consulate general of the republic of Korea in Wuhan in 2012, a large number of Korean enterprises have settled in Wuhan. With South Korea's increasingly frequent economic and cultural exchange, Korean talent relative shortage of Korean the increased demand of learning Korean training institutions into explosive growth, only in Wuhan, there are dozens of Korean education training institutions, relative to other cities will be as understanding of today's society in Wuhan city Korean training present situation research, on the data acquisition and analysis of the more typical and representative, to understand the Korean training in central China, the present situation of the education has important significance.

\section{Investigation and analysis of Korean language training institutions in Wuhan}

By taking Wuhan as the center, in Wuhan each big Korean education training institutions to participate in training personnel as the object of investigation, the questionnaire survey to the distribution characteristics of the development of Korean education institutions analysis from personnel of course of study, research customer needs and feedback, understand the management present situation and the development foreground of industry theory guidance to the development of 
the industry. A total of 1000 questionnaires were issued and 986 valid questionnaires were returned. The survey results are as follows:

\section{1 main components of Korean learners}

The survey first conducted field interviews and questionnaires on the basic conditions of the proportion of men and women, age, social identity and learning motivation. Through analysis we find that, Girls far outnumber boys in the study of Korean in terms of gender. The reason is that, not only in Korean learning, there are more girls than boys in language learning. This depends on differences in brain function between men and women. American psychologist and Nobel Prize winner professor Roger Sperry has conducted a series of experiments on the functional differences between men and women. The results showed that men were superior to women in orientation and position recognition and pattern combination. Women, on the other hand, have better verbal skills, memory and interpersonal skills than men. This suggests that women have an early left brain advantage in developing executive language skills, while men have an early right brain advantage in solving spatial recognition problems. According to the questionnaire and the field visit, the Korean learners are mainly college students. Due to the study or employment development needs of college students, they are aware of the current popular elements through various media and are relatively sensitive to them. In addition, they have sufficient spare time and strong learning ability and other advantages, which all provide various convenient conditions for college students to learn Korean.

\subsection{The expected composition of the faculty}

In the research process, we set 20 questions to evaluate and define the ideal teacher structure from the perspective of customers and education. Through the questionnaire survey of trainees in training institutions, it is found that the teachers expected by the trainees have some characteristics of inclination. Through the analysis of the questionnaire survey results, we found that:

First, Korean learners are more reluctant to accept Korean undergraduate graduates (without any preconditions) as training teachers. In order to further understand the Korean training institutions to participate in the object for the teachers demand, we in the class and participate in the Korean organization focuses on the exchange, in the process of communication, we found that is unwilling to accept the cause of the first degree, as the number of college students show explosive growth, participate in the trainers are not able to accept pure graduates for teaching.

Second, participate in questionnaire mostly influenced by the Korean wave of Korean fans, and want to go to South Korea to study abroad students groups, according to the investigation questionnaire showed that $36 \%$ of the research object is more looking forward to training teachers for the south Koreans, think foreign teachers directly, a professor of Korean more authentic, there are also involved in object represents more willing to accept Chinese, Korean, a professor at understanding will be more clear, thinking more clearly.

Third, Korean language training institutions in the market mainly teach Chinese college students with overseas study experience, mainly responsible for Korean grammar, writing and other courses, followed by Korean foreign students, working as foreign teachers, mainly responsible for correcting pronunciation and exercising students' oral ability.

Fourth, through the communication with the survey participants, we found that the teachers expected by students mainly have the following characteristics: relevant work experience or overseas study experience, as well as relatively strong Korean background professional ability. In addition, we know from talking with the head of Korean training institutions that there is a shortage of Korean teachers. It is also an excellent employment opportunity for students majoring in Korean in Wuhan who have the demand for part-time jobs and full-time employment.

\subsection{Industrial entity teaching of Korean education in Wuhan is parallel with online teaching}

First of all, with the rise of the Internet, although MOOCs and online teaching modes have been vigorously promoted in quite a number of theoretical teaching, the acquisition of skills is very emphasized in foreign language teaching, so interactive Q\&A and repeated training are very 
important. In the initial and intermediate stage of education, face-to-face classroom teaching mode is more practical and efficient. Of course, online teaching and MOOCs can be a useful supplement. Secondly, by comparing video courses and online courses, we find that the current online courses are mainly the learning forms of watching video taught at home and self-study courseware, which are relatively flexible, but the effective learning time is relatively difficult to be guaranteed. However, the effect of concentrated study in physical classroom is relatively good, and teachers are similar. Thirdly, compared with video's video recording, which is usually taught by teachers, face-to-face teaching is undoubtedly superior in terms of interactive communication and Q\&A effect. Simply speaking: face-to-face teaching+video is the best teaching mode combination, face-to-face teaching courses are superior in learning effect, video courses can be viewed repeatedly, not subject to too much restriction of time and environment, and the learning of online courses, its sustainability is also difficult to be guaranteed. Through questionnaires and online survey, we find that: First, although online classes are cheaper than training classes, online classes require higher self-control and self-control, so more Korean learners are willing to choose face-to-face teaching. Second, as a new form of teaching, online courses are also sought after and loved by learners due to their low requirements on learning environment such as time and place. Third, The questionnaire is only distributed to students who teach face-to-face, and there is a certain deviation in the demand of students for online courses. According to the online survey, online courses are also popular among learners of all kinds, and the sales scale is much larger than that of face-to-face courses.

To sum up, Wuhan Korean language training industry has the following three main features: First, the teaching mode is diversified. There are one-to-one, one-to-two, small class, middle class, large class teaching, as well as network courses and other teaching modes. Consumers also have different ideas about what to teach. According to the survey, most of the research subjects prefer the face-to-face teaching type of small class teaching (less than 8 students), because in this teaching mode, students can better absorb knowledge, pay attention and promote learning by organizing some group activities. Teachers can also accurately grasp the learning status of each student, timely make reasonable adjustments. However, other teaching types are also favored by college students, such as individualized one-to-one teaching, large-class teaching (more than 15 students), online course teaching and so on. In general, with the continuous development of science and technology and network technology, college students, as young people in the new era, are exposed to different learning channels, so their choices are also diversified. Second, there are many possibilities for teaching resources. In addition to full-time foreign teachers and professional Korean teachers, there are three possibilities: Koreans working in China and Korean students; Korean entrepreneurs or ethnic Koreans; A graduate or current student majoring in Korean in China. At present, there is a demand for part-time and full-time employment for Korean majors in Wuhan. According to the survey, the majority of students are in the zero-based stage, so the teachers are mostly graduates who have studied in South Korea and graduated from teaching. Some training institutions choose to employ Korean students in Wuhan to teach foreign teachers, correct students' pronunciation, publicize Korean culture and cultivate students' interests. Third, focus on building a quality education brand. As far as the Korean language training institutions in Wuhan are concerned, the Korean language training in Seoul, Starlight, and Sunmoon Education are more popular among college students. These several training institutions have been engaged in small language training for years, in advance to explore the Wuhan Korean training market. 60 percent of respondents reported that they knew Starlight, and Sunmoon Education etc., and positioned these institutions as high-end Korean language training institutions. The survey respondents believe that the courses specially designated by the training institutions for customers are the most attractive, which has been highlighted in the publicity of the training institutions above. There are various ways of publicity, such as issuing flyers, using network platforms such as WeChat public account and recruiting campus agents, etc., which have become its highlights. It can be seen that the charm and motivation of Korean education ultimately lies in high-quality course goods and teaching services. 


\section{The influence of national policies on Korean learning motivation and Korean training business}

Since the THAAD issue emerged in 2016, china-south Korea relations have deteriorated significantly, which has had a negative impact on the operation of current Korean language training institutions and students' enthusiasm for learning Korean. Most managers mentioned the negative impact problem, and the data collection of questionnaire survey also showed this problem.

\subsection{Impacts of THAAD on Korean learners}

Some learners who are prepared to learn Korean may abandon their study of Korean under the influence of the international situation. Through interviews, we learned that some Korean learners had switched to other minor languages, such as Italian, German and French, after the THAAD problem occurred. Korean majors or students are worried about the employment situation and prospect, and change their employment direction by taking the postgraduate entrance examination and civil servant entrance examination.

\subsection{The influence of THAAD on Korean language training institutions}

This is mainly reflected in the reduction of the number of students signing up to learn Korean at a visible speed. The number of applicants is too small to meet the requirement of class opening, so the class cannot be opened. Or teachers waste due to class opening. Some Korean language training institutions also carry out intermediary work to help students to study in South Korea. After the THAAD problem emerged, the number of people applying to study in South Korea decreased significantly.

\subsection{The impact of THAAD on the Korean language education}

With the understanding between the upper political level of the two countries, the negative impact of THAAD on Korean education is gradually fading. However, the heat recovery of Korean education is gradually moving towards rationality and caution, and it is in the state of gradual recovery and development. At the same time, the occurrence of THAAD problem also prompts most Chinese people to view and think rationally about the direction of China-Korea relations, and to conduct in-depth and multi-dimensional examination of Korean culture.

\section{Summary}

The majority of the respondents in this survey are college students. In order to choose Korean as a second foreign language for professional requirements or future career development needs, many foreign language training institutions in Wuhan should grasp the needs of college students as entry point, and seek for customers with goals. According to the survey, the purpose of the college students' group learning Korean is a hobby, 2 it is practical, the vast majority of Korean learners would most want to improve speaking and listening, in order to achieve the use Korean to normal conversation, so suggest the Korean training organizations to strengthen on these two aspects of teaching, and develop the distinctive curriculum plan.

As the main object of Korean training, college students have relatively free time, and Korean training time can be adjusted according to this characteristic, and different teaching time can be set for students to choose. Two times a week, preferably on the weekend or no specific time limit is also favored by them; Holiday, winter and summer vacation focused study is also generally accepted by most students. This class mode is widely available in various Korean language training institutions in Wuhan. For example, Sanshun and starlight have unlimited class time. However, in order to guarantee the Korean language level of customers, even though the class time is unlimited, they should always urge customers to come to learn, constantly improve the Korean language level and consolidate what they have learned. 


\section{References}

[1] Wang Yueying, current situation and future development of Korean education, modern education science, vol.12, pp. 163-164, 2015.

[2] Nie Hongyi, current situation and future development of Korean education, comparative study on cultural innovation, vol.26, pp. 82-84, 2017.

[3] Lou Xiaoqin, problems and countermeasures of Korean education in higher vocational education in Yangtze river delta region, science and technology information, vol.8, pp. 297, 2009.

[4] $\mathrm{Yu}$ Yuanyuan, an organic combination of Korean teaching and cultural construction, heilongjiang science, vol.18, pp. 136-137, 2017.

[5] He Meiping, improving the adaptability of Korean learners' foreign culture through literature education, culture journal, vol.6, pp. 192-202, 2016.

[6] Yan Haijing, intercultural education analysis in Korean language teaching, academic weekly, vol.18, pp. 27, 2015.

[7] Wu Gaoxian, Kang Qiang, problems and countermeasures in cultivating new Korean talents, academic theory, vol.24, pp. 251-252, 2013.

[8] Han $\mathrm{Xu}$, current situation and talent cultivation of Korean language major in Tianjin, journal of education college, vol.8, pp. 150-151, 2012.

[9] Fang Xiangyu, Analysis on employment status and countermeasures of Korean majors, industry and technology BBS, vol.9, pp. 171-172, 2012.

[10]Gong Chunting, a probe into the cultivation of Korean professionals in minor languages, the literary circle (theoretical edition), vol.10, pp. 384-386, 2012. 